\title{
Design and stress analysis of wheeled compactor construction
}

\author{
Lenka Jakubovičová ${ }^{1, *}$, Milan Vaško ${ }^{1}$, Milan Sága ${ }^{1}$, Peter Kopas $^{1}$, Pavol Novák $^{1}$, \\ Marián Handrik ${ }^{1}$ \\ ${ }^{1}$ University of Žilina, Faculty of Mechanical Engineering, Department of Applied Mechanics, \\ Univerzitná 8215/1, Žilina, Slovakia
}

\begin{abstract}
The article deals with the design of compactor for a backhoe loader for middle size excavators. Construction of compactor clamp was designed from heavy gauge sheets which will be welded. For expansion of penetrating into thickening soil there were segments designed on drum. From the point of fatigue during comparison of reached maximal tensions and comparison of these values for several loaded alternatives from Wöhler curve was defined static safety factor.
\end{abstract}

Keywords: subsoil compaction, static analysis, modal analysis, FEM, Ansys Workbench

\section{Introduction}

High-quality subsoil and thickened soil under the building site is an important base of the whole piece of work in civil and building construction engineering. Doing subsoil compaction increases artificially soil density in order not to be overwhelmed by next subside. Simultaneously tightness and imperviousness of soil is increased, and mechanic features are improved. Those required features are achieved by effect of static or dynamic load $[1,2]$.

Compacting machines with their construction, building and load way are right for compaction of various types of soil. There are the following types of soil: cohesive, cohesionless soil and its mixtures [3, 4]. We can divide compacting machines into:

- static rollers (have pressure effect),

- vibratory rollers (have pressure and oscillation effect),

- vibratory boards,

- vibratory rammers,

- explosive punners.

Additional equipment for excavators has multiple use. It is used by work of small to middle extent with the impact on earthmoving and it is generally known as compactors [5].

The article deals with the design of compactor for a backhoe loader with the mass of 8 tons created from affordable price materials.

\footnotetext{
*Corresponding author: lenka.jakubovicova@,fstroj.uniza.sk
} 


\section{Geometric model}

Specification and parameters of compactor are given by demand from practice, Fig. 1, Table 1.

Table 1. Parameters of compactor

\begin{tabular}{|l|l|}
\hline Mass & $400 \mathrm{~kg}$ \\
\hline Work width & $350 \mathrm{~mm}$ \\
\hline Total width & $500 \mathrm{~mm}$ \\
\hline
\end{tabular}

Construction of compactor clamp was designed from heavy gauge sheets which will be welded into needed shape [6,7]. The main part is full steel drum, Fig. 1 (3). For expansion of penetrating into thickening soil there were segments designed on drum, Fig. 1 (4), aimed to disrupt hard layers of drier soil.

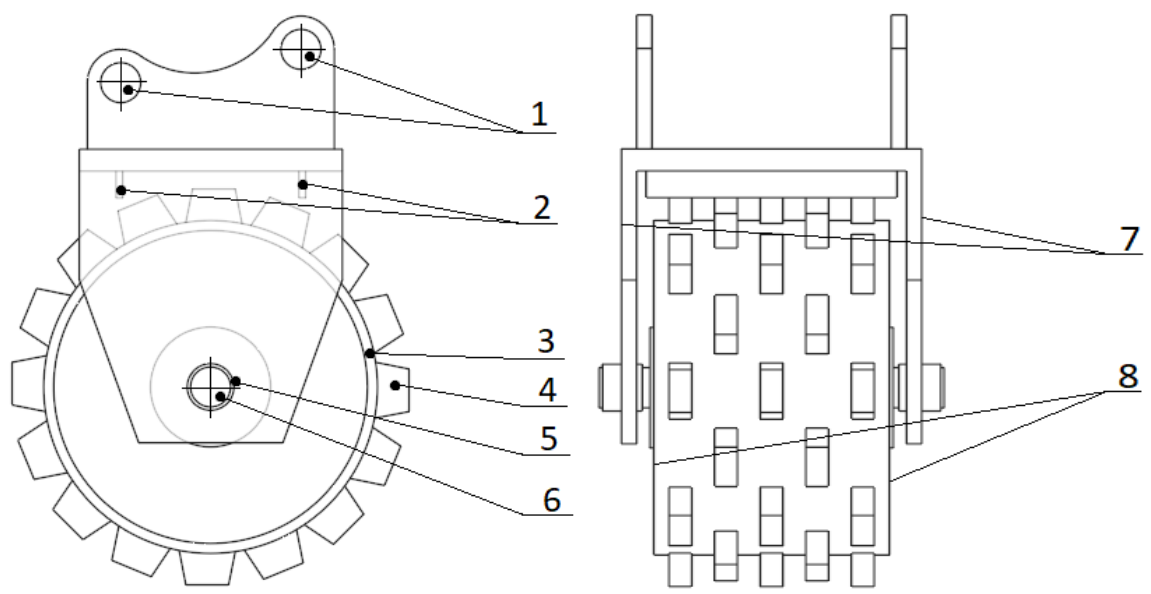

Fig. 1. Compactor assembly: 1 - clamping part; 2 - sediment removal; 3 - drum; 4 - segments; 5 - clamp bushings; 6 - shaft; 7 - cage sidewalls; 8 - drum sidewalls

Using of this mechanism is aimed for loamy to light gravelly soil. Soil characteristics are changeable and reliant on humidity. For the case that there is more humidity in the soil, which causes the soil being sticky, there were sediment removals designed on both sides of cage in the drum rotation way, Fig. 1 (2).

Since it is a welded assembly, the main requirement is weldability and that's why accurate material determination is needed, handling this feature. As accurate material proves material with label S235JRC according to EN 10025 (11 375 according ČSN). Despite the steel is suitable for welding by all commonly used ways, it is needed to pay attention to recommended set conditions for welding.

In order not to lead into drum dent in critical case when being shocked into though subsoil or in the worst case when it leads to the slashing the drum, there were reinforcements located inside the drum. This reinforcements location depends on arrangement of segments on the top side of the drum (Fig. 2).

There are various types of bearings providing the movement of rotating components used in heavy machinery. We distinguish rolling and plain bearings. Between the areas of plain bearing and shaft emerges the friction. Slide bushings, by the help of lubricator provide direct application of lubricant on contact surface, are used for systems of this type in practice. 


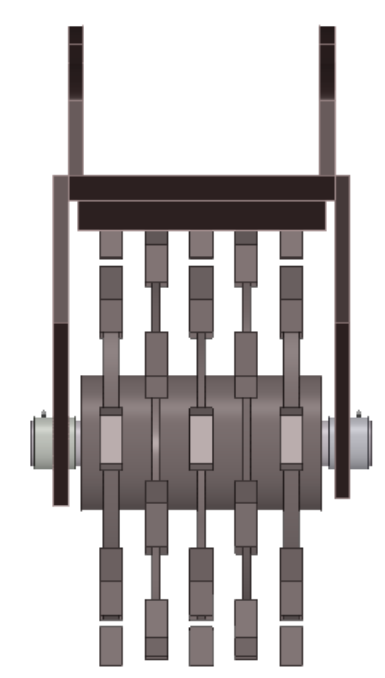

Fig. 2. Placing the reinforcement inside the drum

\section{Finite-element model}

Finite-element model was created on geometry divided into individual volumes using elements SOLID 186. It's a hexahedron quadratic element with twenty nodes, every node has three degrees of freedom $-x, y$ and $z$ displacement. Quadratic elements reach higher accuracy than linear elements with lower number of nodes. On sheet thickness there are at least three elements needed, Fig. 3.

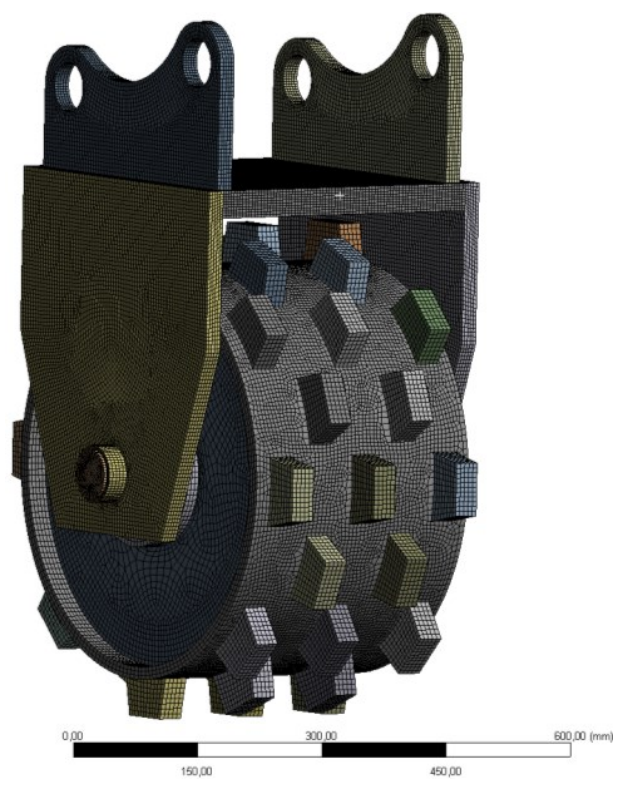

Fig. 3. Finite-element model made as 3D solid body 


\subsection{Define Contact}

Contact with friction between sleeve and shaft was the first contact pair, Fig. 4, [8]. Assigned values are the same on both sides. Coefficient of friction is 0.05 and as the other publications state, the coefficient of friction by dynamic friction of greasy surface is distinguishes according to the lubricant type from 0.029 to 0.12 .

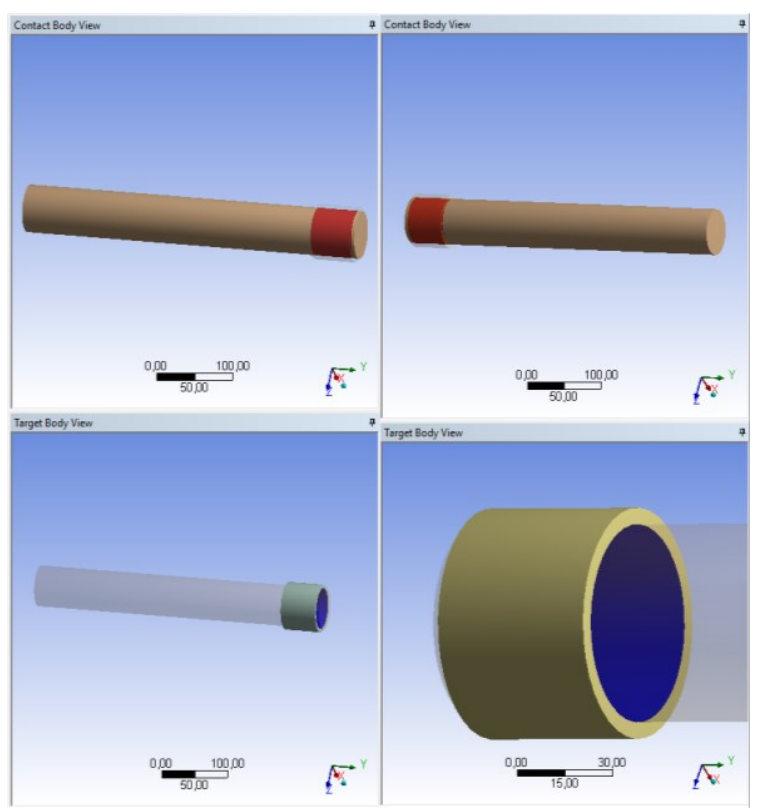

Fig. 4. Contact with friction between shaft and sleeves

As the second contact pair was defined the contact between the sleeve and cage. Because both surfaces aren't mutually moving but they are pressed together, a bonded contact was chosen, Fig. 5.

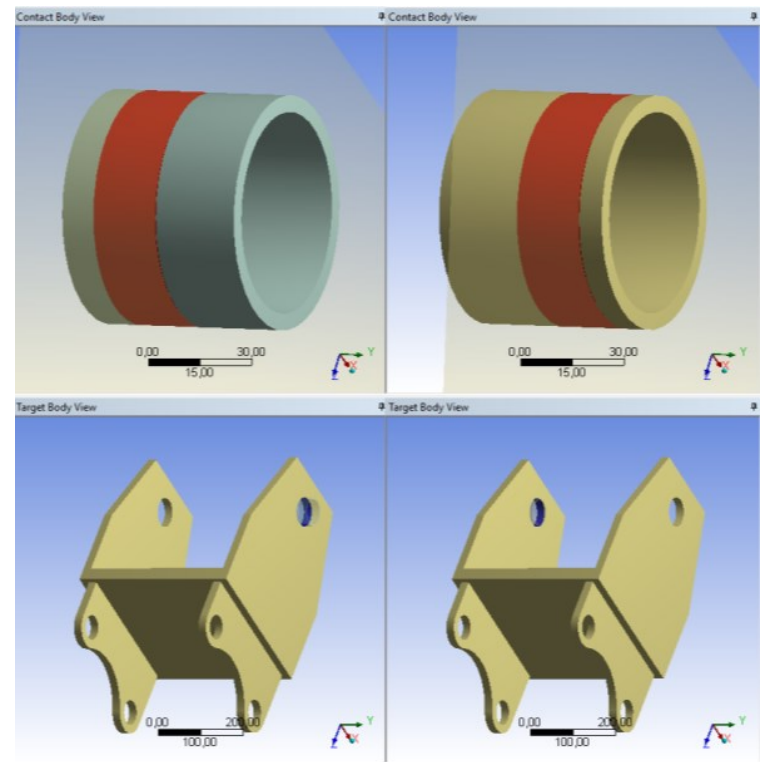

Fig. 5. Bonded contact between cage and sleeves 
The contact between drum and shaft was created as the last contact. The contact type is also bonded because the drum and shaft aren't mutually moving, Fig. 6.

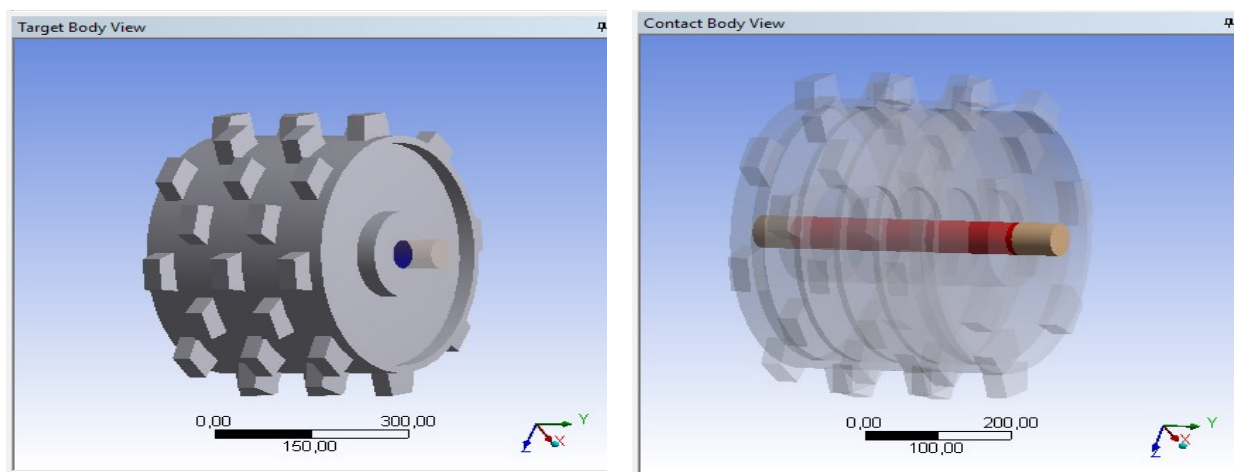

Fig. 6. Bonded contact between drum and shaft

\subsection{Boundary conditions}

Compactor is attached on the arm of backhoe loader by the help of two pins. Their placing and parameters differ from manufacturer and brand of the machine. Degrees of freedom were taken in the direction of axes $x$ and $y$ in the location of pins placing. At the same time there was a force in negative direction of axis $Z$ (vertically downward) applied in those fastenings. The force was divided into 5 steps in values from 0 to $50,000 \mathrm{~N}$. The maximum load corresponds to $2 / 3$ of machine weight. Earth gravity was also included into measurement to gain more accurate results. Finally, all degrees of freedom were taken on various surfaces and edges, which were defined according to the possible load scenarios and they represented the though subsoil, Fig. 7.

The mechanism is loaded by various states in the praxis and on their basis a tension arrangement by stress is evaluated. Newly-emerged deformations and stresses of individual parts of mechanism will be assessed from gathered analysis results according to various types of load. From the results we can change types of used materials and thickness of each sheet which influences the weight of machine itself.

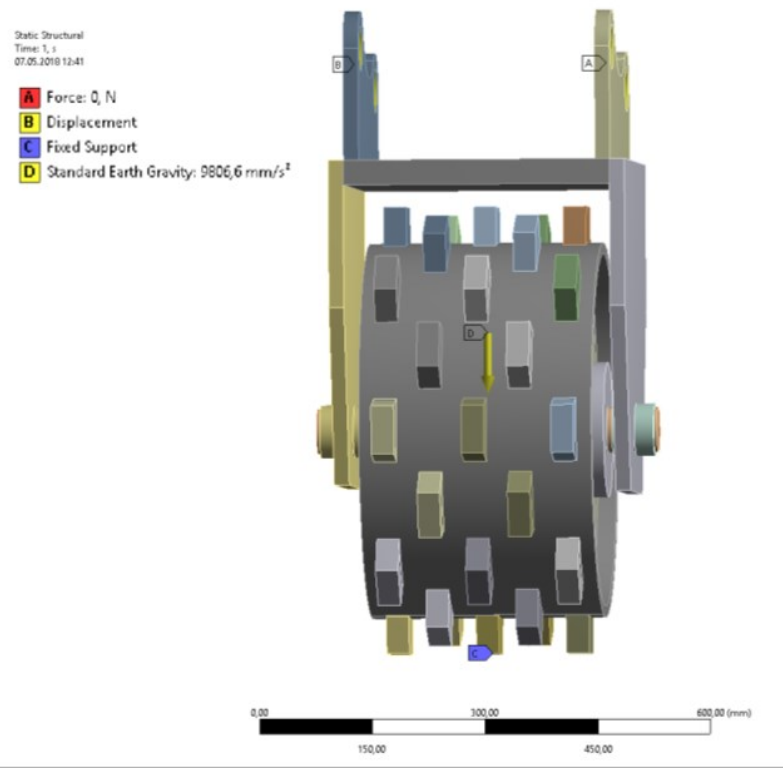

Fig. 7. Boundary conditions 


\subsection{Load on three segments}

Despite this machine is aimed for clayish soil, a case can occur that drum with segments hits the thickened soil - bigger stone and impact force are transferred through meshing segments into lower part of drum.

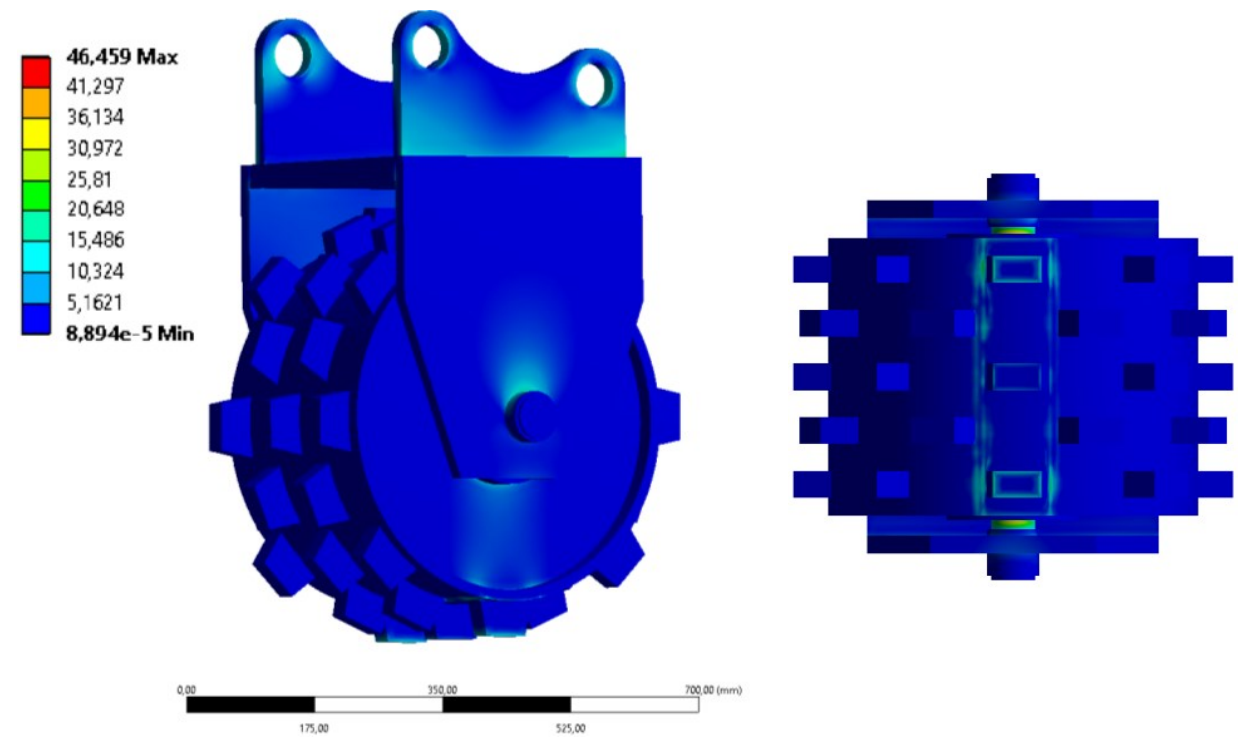

Fig. 8. Von Misses stress, load on three segments

From the sectional view is visible the fact that the biggest load by this type of stress is in the place where shift connects the drum. Load values are lower than $25 \%$ from the value of yield stress for the given material. The other parts of machine are stressed minimally, and this leads us to the point that sheets thicknesses can be adjusted.
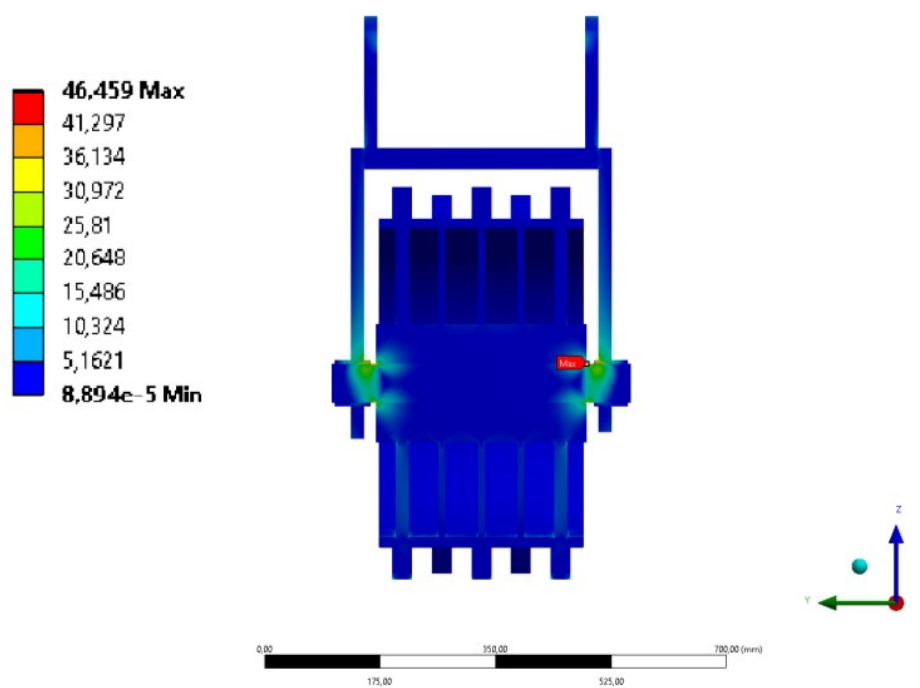

Fig. 9. Load on three segments - sectional view 


\subsection{Load on one segment}

It's the load by the same force as by the previous point, only the force effects the surface of middle segment. Maximal tension by this load type occurred in the place where loaded segment connects the drum. In comparison with previous load more than twofold increase of tension is visible. The biggest load has an effect in the root of segment. Final tensions reach $54 \%$ of the yield stress value which means that material endures given stress. From the point of fatigue during comparison of reached maximal tension $128.9 \mathrm{MPa}$ and comparison of this value with Wöhler curve from the figure 11 is clear that this kind of stress can't be endured by segments endlessly, just approximately 550,000 cycles.
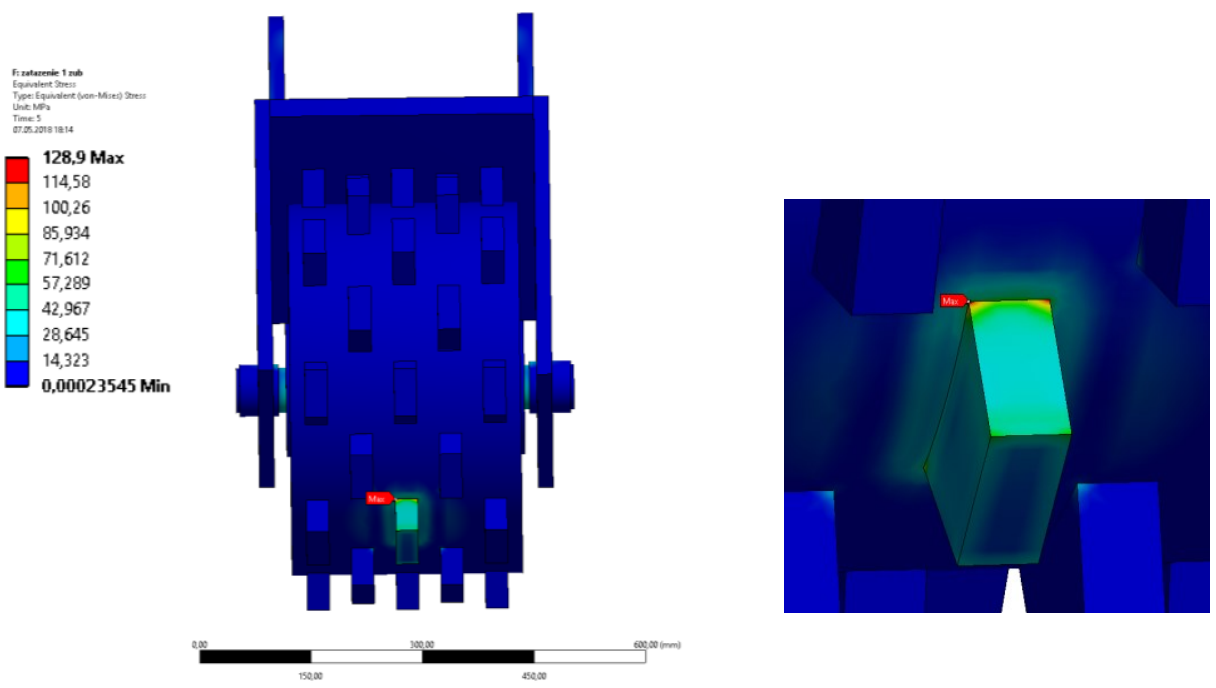

Fig. 10. Bonded contact between drum and shaft

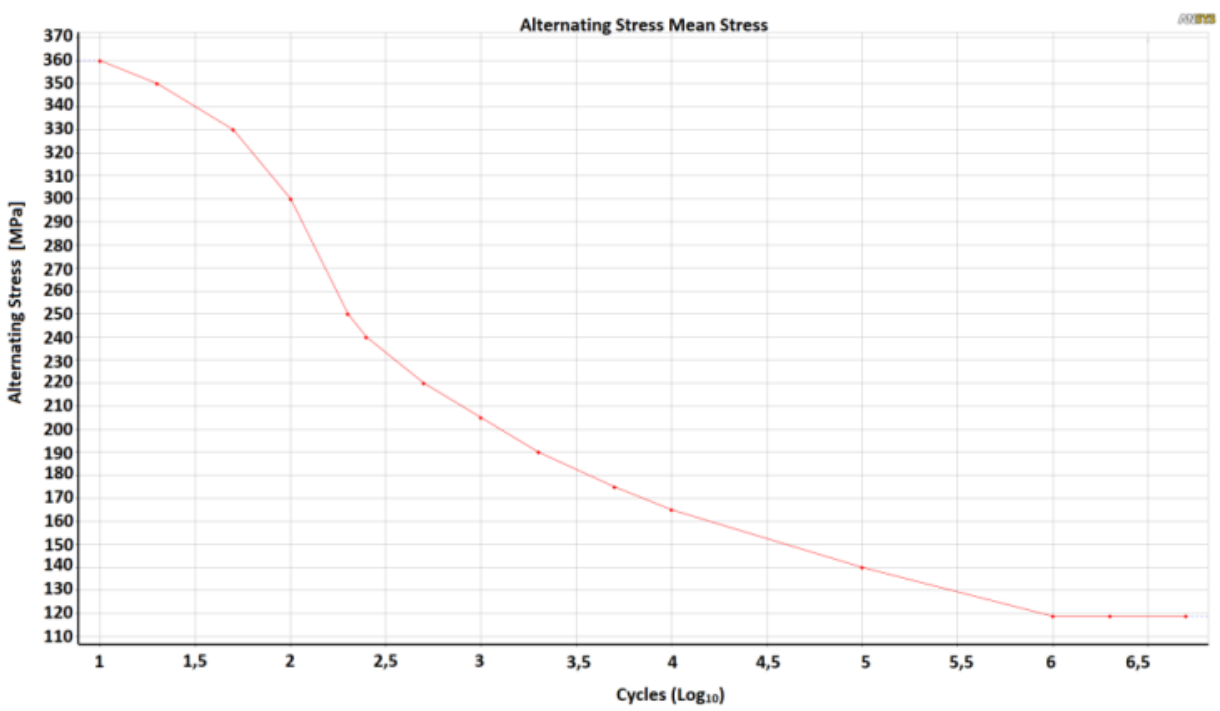

Fig. 11. Wöhler curve of used steel 


\subsection{Load on two segments}

Segments on the surface of drum are designed systematically in lines with two or three items. Next analysis will exactly deal with maximal load having effect on two segments. To simulate perpendicular effect on given segments it was needed to use partially turned around coordinate system.

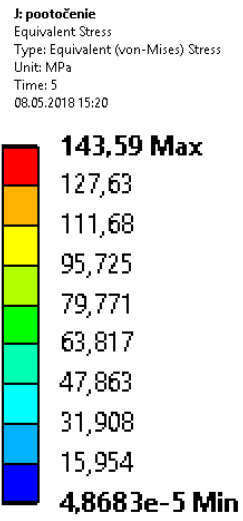

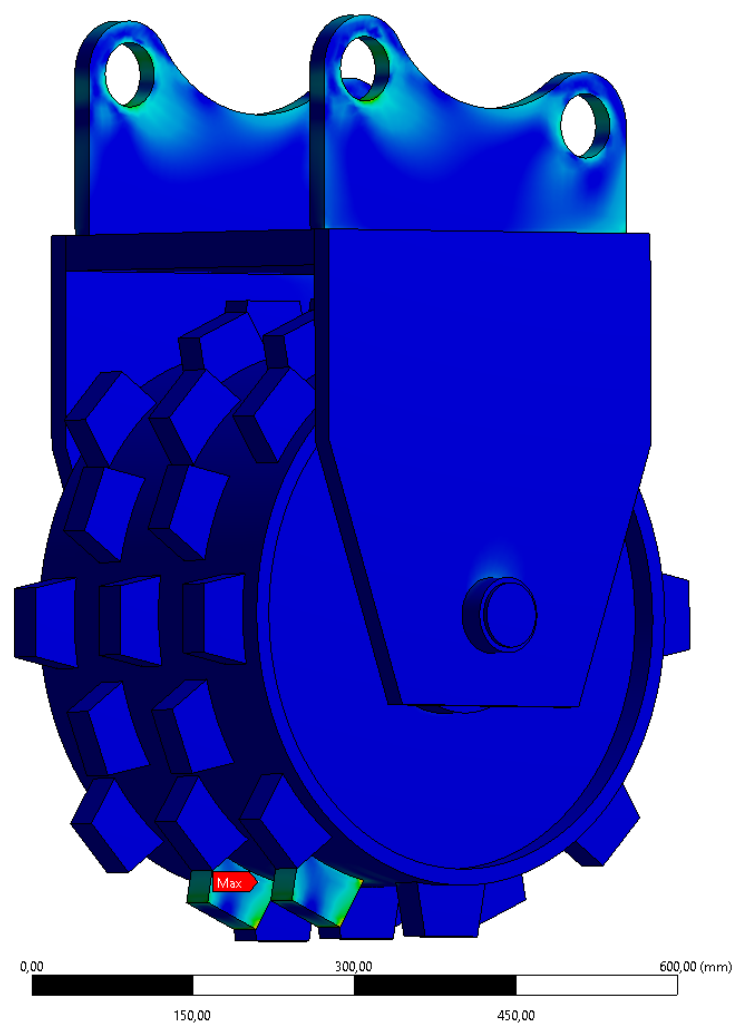

Fig. 12. Load affecting two segments

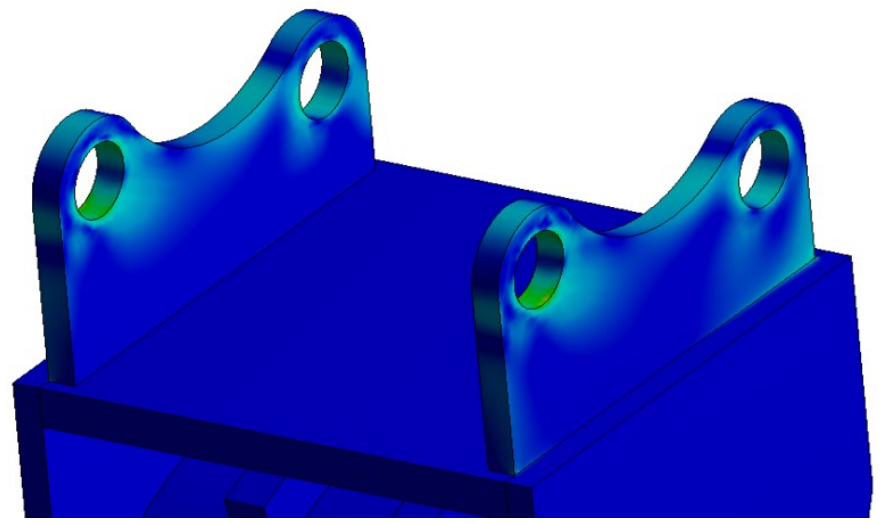

Fig. 13. Detail of fastening by load on two segments 
Final tensions reach $63 \%$ of overall yield stress value which means that material endures given stress. From the point of fatigue during comparison of reached maximal tension 143.59 $\mathrm{MPa}$ and comparison of this value with Wöhler curve from the Figure 11 is clear that segments endure just approximately 500,000 cycles.

The least yield point value of used material was used for results and so lifespan of construction also depends on features of used material. Every manufacturer of materials used for analysing has different final features by production of steel and this fact must be taken into consideration [9-17].

We dealt with the design of additional equipment „compactor“ for excavators with the purpose of soil compaction. Soil compaction is demanding process and equipment which make it need specific compactness. Final layer of compacted soil is found out by the help of Proctor's test after finishing the compaction process. Suggested number of travels to reach needed subsoil compaction in cohesive soil is 9 to 16-times, in non-cohesive soil 7 to 10 times on the same place. Reached thickness of compacted layer $h_{0}$ is by the following calculations.

For cohesive soil

$$
h_{0}=0.09 \cdot \sqrt{\frac{G}{b} \cdot r}[\mathrm{~cm}] \text {, }
$$

for non-cohesive soil

$$
h_{0}=0.12 \cdot \sqrt{\frac{G}{b} \cdot r}[\mathrm{~cm}]
$$

where:

$G-$ roller gravity [N],

$b$ - roller width $[\mathrm{cm}]$,

$r-$ roller radius $[\mathrm{cm}]$.

\section{Summary}

Results of analysis verified that this way designed mechanism holds various loads but also pointed out some machine limits. Even though the mechanism is designated for compaction of clayish soil, it can happen that the soil may contain also bigger stones which cause bigger segment strain and subsequently by repetitive stress the drum can be damaged. Displacement results by various loads have shown inconsiderable amount in tenth millimetres. The mechanism itself is massive enough to comply with loose soil compacting requirements.

This work was supported by the Slovak Research and Development Agency under the contract No. APVV-14-0096 and by grant KEGA 015ŽU-4/2017 - Digital technologies for machine building study programs as a part of strategy "Internet of Things".

\section{References}

1. K. J. Bathe, Finite Element Procedures. (Prentice Hall, New Jersey, 1982)

2. A. Sapietová, V. Dekýš, Dynamic analysis of rotating machines in MSC.ADAMS. Procedia Engineering 136, 143-149 (2016)

3. K. Jeřábek, F. Helebrant, J. Jurman, V. Voštová: Stroje pro zemní práce, silniční stroje, I. vydání. Ostrava: VŠB-TUO, Ostrava 1996. 466 s 
4. J. R. Johanson. A rolling theory for granular solids. Journal of Applied Mechanics 32, $842-848,1965$

5. R. Grega, J. Homisin, J. Krajnak, M. Urbansky, Analysis of the impact of flexible couplings on gearbox vibrations, Scientific journal of silesian university of technologyseries transport 91, 43-50 (2016)

6. W. Piekarska, M. Kubiak, M. Žmindák, Issues in numerical modeling of phase transformations in welded joint. XXI Polish-Slovak Scientific conference machine modeling and simulations MMS 2016, Procedia Engineering, 177, 141-148 (2017)

7. P. Kovacikova, R. Bezdedova, J. Jr.Vavro, J. Vavro, Comparison of numerical analysis of stress-strain states of cast iron with vermicular graphite shape and globular graphite shape. 20 th International conference machine modeling and simulations MMS 2015, Procedia Engineering 136, 28-32 (2016)

8. M. Dudziak, G. Domek, A. Kołodziej, K. Talaśka, Contact Problems Between the Hub and the Shaft with a Four-Angular Shape of Cross-Section for Different Angular Positions, Applied Mechanics and Materials 816, 54-62 (2015)

9. R. Grega, J. Krajňák, L. Žul'ová, G. Fedorko, V. Molnár, Failure analysis of driveshaft of truck body caused by vibrations. Engineering Failure Analysis 79, 208-215 (2017)

10. L. Zul'ova, R. Grega, J. Krajňák, G. Fedorko, V. Molnár, Optimization of noisiness of mechanical system by using a pneumatic tuner during a failure of piston machine. Engineering Failure Analysis 79, 845-851 (2017)

11. E. Kalentev, Š. Václav, P. Božek, A. I. Korshunov, V. Tarasov, Numerical analysis of the stress-strain state of a rope strand with linear contact under tension and torsion loading conditions. In Advances in Science and Technology Research Journal. 11, Issue 231-239 (2017)

12. V.P. Mateichyk, V.P. Volkov, P.B. Komov, I.V. Gritsuk, et al. Special features of vehicle condition monitoring using onboard diagnostics systems. Project management, systems analysis and logistics, scientific journal, NTU, 13, 126-138 (2014)

13. Y. Turygin, P. Božek, I. V. Abramov, Y. R. Nikitin, Reliability determination and diagnostics of a mechatronic system. In Advances in Science and Technology Research Journal. 12, Issue 2, 274-290 (2018)

14. P. Krawiec, G. Domek, Ł. Warguła, K. Waluś, J. Adamiec: The application of the optical system ATOS II for rapid prototyping methods of non-classical models of cogbelt pulleys. In: MATEC Web of Conferences, 157, art. no 01010 (2018)

15. P. Krawiec, Numerical Analysis of Geometrical Characteristics of Machine Elements Obtained Through CMM Scanning, Progress in Industrial Mathematics, SpringerVerlag, Berlin-Heidelberg, 925-930 (2010)

16. Flizikowski J., Macko M., Czerniak J., Mroziński, A.: Implementation of genetic algorithms into development of mechatronic multi-edge's grinder design, ASME 2011 International Mechanical Engineering Congress and Exposition, IMECE, Nov. 11-17, 2011, Denver, Colorado, USA

17. R. Halama, J. Podešva, R. Suzuki, M. Matsubara, R. Čech, Mechanics of Herbert Pendulum Hardness Tester and its Application. In: Engineering Materials, 741, 122-127 (2017) 